\title{
Análise do Processo de Artificialização do Município de Balneário Camboriú, SC, Brasil *
}

\section{Analysis of the Artificialization Process of Balneário Camboriú City, SC, Brazil}

\author{
Laura Piatto $^{@, 1}$, Marcus Polette ${ }^{1}$
}

\section{RESUMO}

A artificialização é um processo dinâmico de transformação da paisagem natural num certo período de tempo. Esse processo ocorre sempre que o homem altera o espaço de acordo com as suas necessidades e disponibilidade de recursos. $\mathrm{O}$ rápido crescimento populacional nas regiôes litorâneas está acelerando o processo de artificialização da zona costeira, tornando esses ecossistemas o mais urbanizado de todo o mundo. A orla marítima, mesmo compondo uma pequena parte da zona costeira, é o elo entre a vida terrestre e marinha. Essa característica é atraente não somente para a rica biodiversidade que a compóe, mas também para o homem. Portanto, as orlas devem ser prioritariamente ordenadas e regulamentadas, para garantir um desenvolvimento sustentável, evitando o esgotamento de sua capacidade de carga. Desta forma, o presente trabalho tem como estudo uma relevante área do litoral Centro-Norte Catarinense, onde a artificialização se faz presente: Balneário Camboriú. O objetivo deste estudo foi analisar o grau de artificialização do município de maneira quantitativa, através da análise de ocupação do solo por vetorização utilizando imagens de satélite, o que proporciona um maior detalhamento e definição dos diversos níveis de artificialização. Para isso, o município foi dividido em unidades de paisagens e subdividido em trechos, para então ser classificado em quatro níveis de artificialização: Natural, Semi-natural, Semi-artificial e Artificial. O estudo revelou que o município de Balneário Camboriú apresentou uma unidade Artificial e duas unidades Semi-naturais. Após essa classificação quantitativa, foi possível comparar a metodologia do presente trabalho à metodologia do Projeto Orla, o qual classifica os mesmos trechos da área de estudo qualitativamente, realizada por meio de identificação visual das unidades. A comparação comprovou a maior eficiência no sistema quantitativo de classificaçâo da orla marítima, o qual pode vir a complementar às análises do Projeto Orla, validando sua classificaçáo qualitativa com valores concretos de percentual de ocupação.

Palavras chaves: Artificializaçāo, Orla marítima, Projeto Orla, Zona Costeira.

\section{ABSTRACT}

Artificialization is a dynamic process of transformation of the natural landscape in a given amount of time. This process always takes place when humans alter a space in accordance with their needs and resources availability. The fast population growth of coastal areas is speeding the artificialization process of coastal zones, turning these ecosystems into the most urbanized ones in the world. Although the coastline is a just a small portion of the coastal zone, it is the link between the terristrial and sea lives. This feature is not only attractive to the rich biodiversity which

@-Autora correspondente: Lpiatto@yahoo.com.br

1 - Universidade do Vale do Itajai - UNIVALI, Laboratório de Gerenciamento Costeiro Integrado 
it is formed by, but also to humans. Therefore, coastlines must primarily be ordened and regulated in order to ensure sustainable development, avoiding the exhaustion of its capacity. Thus, this work studies a relevant area of the mid-north coast of the state of Santa Catarina, where we can find artificialization: Balneario Camboriu. The objective of this work was to make a quantitative analysis of the degree of artificialization of this citie, analyzing land use by vectorization using satellite images, which allows for greater detail and definition of the different levels of artificialization. For this purpose, the citie was divided into landscape units and subdivided into zones, and, then, classified into four levels of artificialization: Natural, Semi-natural, Semi-artificial, and Artificial. Then, a databank of was created, quantifying the distinct categories of occupation and distribution of the different degrees of artificialization in the area. One artificial and two semi-natural units were found in Balneario Camboriu. The artificial area is at its occupation limit, compromising the future of the semi-natural areas, which may become targets of the real estate and civil construction industries. This result reflects the intense densification of the coastline, where occupation conflicts with the capacity of supporting its already-over-exploited resources. After this quantitative classification, we compared the method used in this work and that used by Project "Orla" (a project by the Federal Goverment, supervised by the Coastal Management Integration Group - GI-GERCO), which qualitatively classified the same area by means of visual identification of the units. The comparison showed that the quantitative system of classification of the coastline was more efficient and can complement the analyses of Project "Orla", validating its qualitative classification with concrete percentages of occupation. The method of visual analysis of high-definition imagens proved to be a good tool for soil occupation classification. Thus, we developed a cheap method, which can be used both in coastline projects, such as Project "Orla", and in urban planning projects by any city government.

Keywords: Artificialization, Littoral fringe, Project "Orla", Coastal Zone

\section{INTRODUÇÁO}

A palavra "artificializaçáo" surgiu frente à necessidade de conceituar o rápido ação do homem na transformação sobre o que é natural, podendo ser empregada em várias áreas da ciência: saúde, social, química, física, entre outros. Porém, no processo de ocupação do solo, a artificialização se enquadra num contexto econômico, social e principalmente ambiental, pondo em questão a sustentabilidade do ambiente alterado.

Para Silva (2007), a artificialização é um processo dinâmico de transformação da paisagem natural num certo período de tempo. Esse processo ocorre sempre que o homem altera o espaço de acordo com as suas necessidades e disponibilidade de recursos. Segundo Lacasa (2009), essas transformaçóes podem ser através da "incorporaçáo ou extração de elementos, os quais não podem aparecer naturalmente no processo evolutivo sem a intervenção humana."

Assim as áreas costeiras situam-se como áreas preferidas para assentamentos humanos, pois propiciam acesso para as rotas marinhas e ligam-se ao mundo. As zonas costeiras são os ecossistemas mais urbanizados, com $65 \%$ dos habitantes vivendo em áreas urbanas. Europa, América do Norte, Oceania e América Latina têm as maiores áreas costeiras urbanizadas, com mais de $80 \%$ da população vivendo em cidades ao longo da linha da costa (UN-HABITAT, 2008). Esta intensa ocupação global da zona costeira é citada por muitos autores. Em MEA (2005), por exemplo, indica-se que em 2000, a densidade populacional mundial na área costeira era de aproximadamente 100 pess, oas $/ \mathrm{km}^{2}$, enquanto que no interior a densidade era de 38 pessoas $/ \mathrm{km}^{2}$.

Segundo a European Evironment Agency (EEA, 2006), no continente europeu a população costeira cresce mais rápido do que no interior do continente. Entre 1990 e 2000, a artificializaçáo cresceu em quase todos os países da Uniáo Européia, sendo 25\% maior na costa, num total de 190 quilômetros quadrados por ano. $\mathrm{O}$ resultando foi um aumento de $61 \%$ na ocupaçáo do território europeu. Esse processo se deu através da reestruturação econômica, que levou os países ao desenvolvimento, atraindo a expansão residencial.
Países citados como área de estudo, por seus respectivos autores, são cenários do alto índice populacional e de conseqüente expansão urbana que invade o litoral e desfigura a paisagem natural antes presente. São alguns deles: Espanha (Zújar \& Lama, 2006; Herrero, 2008; Sanjaume \& Pascual, 2008), Portugal (Alves et al., 2007), Uruguai (Marrubio, 2004) e Japão (Uda et al, 2007).

A transformação da terra em superfície artificial é mais intensa no primeiro quilômetro da linha da costa. De entre os países que compóem os estudos da EEA (2006), o crescimento mais rápido foi em Portugal (34\%), Irlanda (27\%) e Espanha (18\%), seguida pela França, Itália e Grécia. Na Itália, França e Espanha, a média de áreas construídas nos primeiros quilômetros de costa já excede $45 \%$.

Fatores como crescimento populacional, localizaçáo geográfica, êxodo rural, políticas nacionais e outras políticas sociais e econômicas provocam o aumento da urbanização e construção de infra-estruturas. Comunidades e indústrias estão investindo cada vez mais no potencial de exploração da zona costeira: pescado, óleo, gás natural, areia, minerais, aqüicultura, habitação, turismo e lazer. Através desse crescimento econômico, indústrias, complexos turísticos e a especulação imobiliária iniciam a transformação do modelo urbanístico de ocupação do litoral, investindo na verticalização de edificaçôes e no incremento de superfícies artificializadas.

Paradoxalmente a sociedade que é atraída pela qualidade de vida, pelo turismo e pelas áreas ainda conservadas, com natureza abundante, ar puro, matas virgens e água limpa, também é responsável pelo acelerado uso e ocupação da costa (Polette, 2004). Assim, a descaracterização das paisagens é inevitável, colocando freqüentemente em risco o próprio patrimônio gerador de seu atrativo turístico devido a formação de áreas precariamente urbanizadas, cujas praias movimentadas e poluídas durante o verão possuem sua resiliência fortemente afetada.

Oavanço da ocupaçãodeformadesordenada, incompatível com a capacidade de suporte, tem como conseqüência danos imensuráveis: poluição marinha, desmatamento, perda de 
biodiversidade, alteração do ciclo hidrológico, enchentes, erosão, poluição do lençol freático, eutrofização de sistemas associados (como lagoas e lagunas) e blooms de algas nocivas. "Com maior ou menor intensidade, pode-se citar a formação de micro-climas nos centros urbanos, relacionado com o adensamento de construçóes, enchentes, lixos acumulados, poluição hídrica, visual, atmosférica, congestionamentos, entre outros" (Silva, 2007).

O litoral de Santa Catarina também tem sido influenciado pelo processo de urbanização da zona costeira. Balneário Camboriú é um dos municípios afetados com essa transformação da paisagem, apresentando um dos maiores índices de crescimento demográfico e urbano de todo o estado. Este rápido crescimento ocorreu a partir da tríade construção civil, turismo e setor imobiliário levando ao incremento do processo migratório e adensamento populacional. No entanto, é na orla que estes setores econômicos atuam de forma decisiva, pois a qualidade da paisagem, aliada ao valor imobiliário, leva ao adensamento e à verticalizaçáo. Neste cenário de grandes empreendimentos e saturaçáo dos espaços, a artificialização da orla do município de Balneário Camboriú ocasionou impactos negativos dos mais diversos graus.

Com o objetivo de dimensionar essa transformação da paisagem, foi analisado o processo e o grau de artificializaçáo deste setor costeiro tendo como referência a faixa de 300 metros de ocupação da orla marítima do município de Balneário Camboriú, com base na metodologia de Lacasa, (2009).

A metodologia aplicada por Lacasa (2009) foi utilizada na Península de Porto Belo, obtendo dados satisfatórios e condizentes com a realidade da região. Neste trabalho foi analisada a ocupaçáo do solo por vetorização utilizando imagens de satélite, o que proporciona um maior detalhamento e definição dos diversos níveis de artificialização. Após essa classificação quantitativa, foi possível comparar a metodologia do presente trabalho com a metodologia do Projeto Orla, o qual classifica os mesmos trechos da área de estudo qualitativamente, realizada por meio de identificação visual das unidades.

A contribuição do presente trabalho está em aprofundar o método, replicar o mesmo para outro setor costeiro e buscar com que a presente metodologia possa inclusive ser adotada como base para as políticas públicas que incidem na orla brasileira, como é o caso do Projeto Orla.

\section{MATERIAL E MÉTODOS}

\section{1 Área de estudo}

A área de estudo deste trabalho compreende o município de Balneário Camboriú, situado no litoral Centro-Norte do Estado de Santa Catarina, Brasil (Figura 1). O turismo na região iniciou-se na década de 1950 , mas se intensificou nos anos de 1970, com a construção da BR-101. Desde então Balneário Camboriú sofre com o aumento da população flutuante, que no verấo chega a ser dez vezes superior à populaçáo fixa. $\mathrm{O}$ sistema de saneamento do município não suporta o incremento sazonal da população, pois é planejado apenas para suprir a população residente. Recursos como água e luz muitas vezes chegam a faltar na época de veraneio.

Atualmente, o município possui a maior concentraçáo urbana e o maior pólo turístico do Sul do Brasil. É o sétimo destino turístico do país, destancando-se como um dos maiores pólos turísticos do Mercosul, onde mais de 1.500.000 de turistas circulam todo ano. O setor terciário, como as atividades turísticas e o comércio, é responsável por $99,21 \%$ da economia e motiva o setor secundário, cuja principal atividade é a indústria da construção civil (Prefeitura Municipal de Balneário Camboriú, 2003).

Uma planilha com projeçôes do crescimento da população catarinense, divulgada pela Secretaria de Planejamento do Governo do Estado, revela que, entre o censo oficial de 1996 e 2006, o Estado passou de 4,8 milhóes para 5,9 milhóes de habitantes. O crescimento foi de $22,1 \%$. O portal jornalístico internet Noticenter cruzou os dados de todos os municípios e constatou que Balneário Camboriú lidera o crescimento entre os 30 maiores nesse período. A cidade

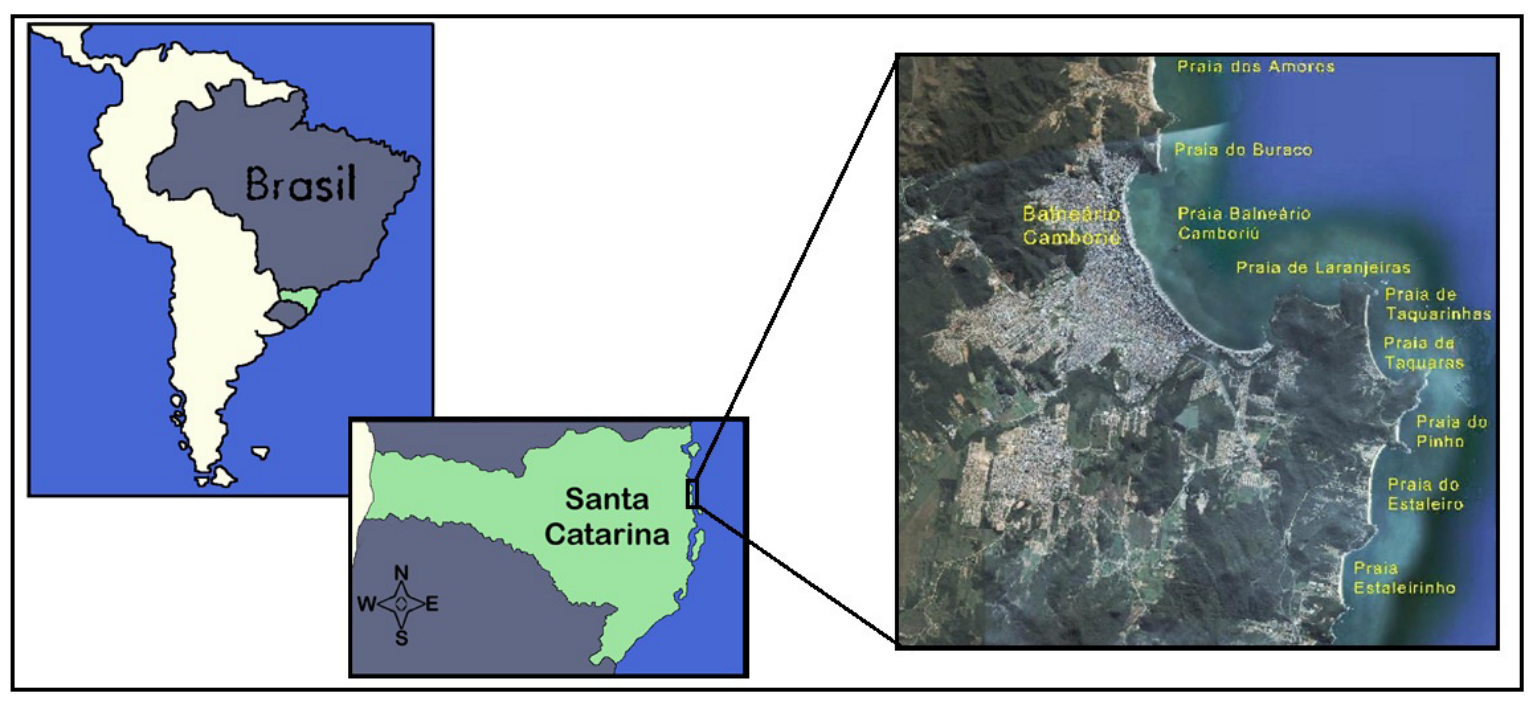

Figura 1. Mapa da área de estudo.

Figure 1. Map of study area. 
cresceu 68,3\% em apenas 10 anos, passando de 58 mil para 99 mil habitantes.

Paralelamente ao turismo, a especulação imobiliária e a construção civil também registraram rápido crescimento. Empreendimentos milionários refletem o potencial de atração paisagística da regiáo. Ricos investidores, interessados inicialmente pela qualidade de vida que municípios como Balneário Camboriú proporcionam, compram imóveis que em menos de dois anos chegam a duplicar o valor. Essa supervalorizaçáo gerou um ciclo de compra e venda que estimula a construção desenfreada.

\subsection{Delimitação da área de estudo}

\subsubsection{Orla Marítima}

Neste trabalho, a delimitação da orla marítima é de 300 m, a partir da linha de costa. Esta medida foi estabelecida a fim de englobar a área determinada pelo Projeto Orla e a área determinada pela Resolução CONAMA no 303/2002.

\subsubsection{Unidades de paisagem}

Baseado na metodologia do Projeto Orla foram destacados unidades da paisagem, podendo ser configuradas de duas formas: unidade de paisagem definida claramente por estruturas do suporte físico, como falésias, morros, etc. e/ou aquela cuja configuração é estabelecida pelas características de cobertura, tanto de vegetação (nativa ou não), quanto de urbanização. Após a divisão das unidades de paisagem, foi feita a subdivisão da orla em trechos, facilitando sua classificação e o delineamento das futuras açóes de gestão de cada segmento. (Zamboni \& Vilanova, 2006).

\subsection{Escalas}

Três diferentes escalas foram adaptadas, de acordo com cada etapa do projeto:

- 1:2500: Escala de classificação dos objetos: a partir desta escala foram feitas as interpretaçóes e classificaçôes da área de estudo, usando a nomenclatura criada para definir o tipo de ocupação.

- 1:25000: Escala de tomada de decisão: nessa escala é possível analisar os segmentos das Unidades de Paisagem com detalhamento suficiente para delinear futuras açóes de gestão.

- 1:8.0000: Escala de compreensão (global): esta escala facilita o entendimento geral de todo o território e ilustra o Grau de Artficialização de todos os trechos.

\subsection{Unidade mínima}

O tamanho da unidade mínima pode ser representado dependendo da escala e da resolução da imagem. Neste trabalho, a unidade mínima foi referida como a superfície na qual o nível de interferência humana não pode ser determinado facilmente dentro das características da imagem de alta resolução. Por exemplo, alguns tipos de degradação (erosão, poluição, espécies exóticas) com efeitos difíceis de visualizar. Neste caso, durante as classificaçóes dos objetos na escala 1:2500, áreas abaixo de $50 \mathrm{~m}^{2}$ não definidas, sofrem homogeneização, sendo incluídas no parâmetro mais próximo.

\subsection{Nomenclatura Utilizada}

A elaboração das classes e suas respectivas legendas (cores) foram adaptadas do Corine Land Cover (CLC), por ser o método de análise de cobertura e uso do solo mais reconhecido e utilizado por vários autores em todo o mundo.

O Sistema de Classificação Land Cover (Land Cover Classifcation System - LCCS) foi criado para ser implementado em todo o Globo (Lacasa, 2009) e foi adaptado para este trabalho, com a intenção da padronização internacional das nomenclaturas. A classificação original do CLC possui 44 classes, seus mapas de uso e ocupação do solo são feitos na escala 1: 100 000, por dados vetorial, muitas vezes por dados raster e fotografias aéreas (Bossard et al., 2000).

Foram criadas 32 classes no método Lacasa (2009). Porém, ao realizar as classificações em Balneário Camboriú, apenas algumas destas classes foram encontradas, já que as nomenclaturas criadas basearam-se em todo o Litoral Centro-Norte de Santa Catarina.

\subsection{Determinaçáo do grau de artificializaçáo}

Nessa fase do trabalho, foram utilizadas duas etapas para definir o Grau de Artificialização da orla do município de Balneário Camboriú:

- Determinação do Nível de Artificialização por tipo de classe

- Determinação do Grau de Artificialização por unidade de paisagem

\subsubsection{Determinaçáo do Nível de Artificializaçáo por tipo de classe}

Com a intenção de reduzir dúvidas e subjetividades, foi aplicado o Método Delphi, também conhecido como Ranking. Este método é baseado em estimativas de um grupo de especialistas, os quais são cuidadosamente selecionados pela sua experiência, respondendo a um questionário em um ou mais ciclos. Neste caso, cinco diferentes profissionais estipularam valores às distintas classes segundo o conceito de artificialização. Os especialistas, formados em diversas áreas relacionadas com o tópico, responderam ao questionário individualmente baseando-se no seu conhecimento, ajudando assim no desenvolvimento da classificação.

Cada especialista classificou 20 classes da legenda com pesos de 0 (menor) a 4 (maior) conforme os níveis crescentes de artificialização (Tabela 1). Como os Espaços Naturais não têm traços artificiais, as classes pertencentes a essa categoria não estão incluídas.

Tabela 1. Valores dos Níveis de Artificialização.

Table 1. Values of the Artificialization Level.

\begin{tabular}{|c|c|}
\hline Valores dos pesos & Níveis de Artificialização \\
\hline $0<\mathrm{X}<1,5$ & Baixa \\
\hline $1,5<\mathrm{X} \leq 3$ & Média \\
\hline $3<\mathrm{x} \leq 4$ & Alta \\
\hline
\end{tabular}


O objetivo foi chegar a um consenso entre o painel dos especialistas. $\mathrm{O}$ peso final de cada parâmetro é a média dos valores apresentados pelos profissionais consultados.

\subsubsection{Determinaçáo do grau de artificializaçáo por unidade de paisagem}

O Grau de Artificialização desse trabalho é obtido mediante o quociente de dois valores: Porcentagem de áreas Naturais / Artificiais e Porcentagem de ocupação com classes de Alta Artificialização.

Nessa classificação, propóem-se quatro diferentes Graus de Artificialização para cada unidade de paisagem: Natural, Semi-Natural, Semi-Artificial e Artificial. O Método Delphi (painel de especialistas) foi novamente utilizado para atribuir um limite para delimitar valores (máximo e mínimo), porém neste caso, sua função foi definir os quatros níveis da classificação final. Outra vez, chegou-se a um consenso entre os valores estabelecidos por cada especialista para determinar os limites dos quatro Graus de Artificialização. O limite final das porcentagens está definido na Tabela 2 .

Tabela 2. Limite das porcentagens de cada Nível de Artificialização. Table 2. Range of percentages for each degree of Artificialization.

\begin{tabular}{|c|c|c|}
\hline $\begin{array}{c}\text { \% OCUP } \\
\text { NAT/ART }\end{array}$ & $\begin{array}{c}\text { \% ALTO NÍVEL } \\
\text { ART }\end{array}$ & CLASSIFICAÇĀO \\
\hline$>91$ & $<5$ & Natural \\
\hline $91 \geq \mathrm{X}>67$ & $5 \leq \mathrm{x}<12$ & Semi-natural \\
\hline $67 \geq \mathrm{X}>30$ & $12 \leq \mathrm{x}<25$ & Semi-artificial \\
\hline$\leq 30$ & $\geq 25$ & Artificial \\
\hline
\end{tabular}

Uma área determinada com $93 \%$ do seu território coberto por classes Naturais, porém tendo 5\% dos espaços com Alto Nível de Artificialização corresponde ao Nível Semi-natural. Portanto, para classificar um trecho e posteriormente uma unidade, foi necessário observar sua porcentagem de ocupação Natural/Artificial e a porcentagem de ocupação do Alto Nível de Artificialização, pois dependendo do caso, a porcentagem da segunda pode sobrepor consideravelmente sobre a primeira e vice-versa, classificando o Grau de Artificializaçáo por unidade de paisagem para um nível menos favorável.

Desta forma, foi possível visualizar o Grau de Artificialização de cada unidade de paisagem do município de Balneário Camboriú.

\subsection{Georeferenciamento}

As imagens foram gentilmente cedidas pelo Laboratório de Sensoriamento Remoto e Geoprocessamento da UNIVALI. Foram adquiridas imagens de alta resolução (2,4 metros) do satélite QUICKBIRD através do software Google Earth, do ano de 2002 e padronizadas do ponto de visão de $3 \mathrm{~km}$ de altitude.

Para vetorização das imagens e processamento dos dados foi utilizada a ferramenta ArcMap 9.2 do software ArcGIS 9.2.

\section{RESULTADOS E DISCUSSÃO}

A orla de Balneário Camboriú, analisada na faixa de 300 metros a partir da linha de costa, totalizou em 9.335.658,674 $\mathrm{m}^{2}$ de área de estudo, apresentado 20 classes agrupadas em 5 categorias (Tabela 3).

Esta porção da orla marítima possui $36 \%$ do seu território com algum tipo de alteração/efeito antrópico, porém 64\% ainda permanecem como Espaços Naturais, sendo a maior parte constituída por áreas vegetadas. Esse valor surpreendente está relacionado com a morfologia da costa, a qual apresenta áreas recortadas, de difícil acesso, conseqüentemente, de difícil ocupação.

A categoria Áreas Residenciais está mais presente na planície costeira de Balneário Camboriú, a qual possui uma ocupação de mais de $74 \%$ do seu território. Contudo, essa área é quase 3 vezes menor se comparada com as regióes em relevo.

Em Balneário Camboriú a estrada BR 101 também foi projetada paralelamente à costa. Porém, não se localiza dentro dos $300 \mathrm{~m}$ de orla. A Área Urbana Verde participa com apenas $0,44 \%$ nessa categoria, caracterizando canteiros de avenidas, rotatórias e representando uma porcentagem muito pequena de estruturas para recreação.

Tabela 3. Classes do Município de Balneário Camboriú. Table 3. Occupation classes from the edge of the city of Balneário Camboriú.

\begin{tabular}{|l|c|c|}
\hline \multicolumn{1}{|c|}{ CLASSES } & ÁREA $\left(\mathbf{m}^{2}\right)$ & $\%$ \\
\hline Espaços naturais & 5957811,242 & $63,82 \%$ \\
\hline Dunas & 4890,4726 & $0,05 \%$ \\
Praia & 546395,1162 & $5,85 \%$ \\
Costão rochoso & 317251,8469 & $3,40 \%$ \\
Floresta Ombrófila densa & 4096811,677 & $43,88 \%$ \\
Formação pioneira com influência marinha & 510534,306 & $5,47 \%$ \\
Formaçăo pioneira com influência flúvio-marinha & 97369,6688 & $1,04 \%$ \\
Curso d'água & 384558,1539 & $4,12 \%$ \\
Lagoa & 0 & $0,00 \%$ \\
\hline Espaços semi-naturais & 317411,109 & $3,40 \%$ \\
\hline Espaço natural alterado & 76918,3394 & $0,82 \%$ \\
Espaço natural muito ailterado & 240492,7696 & $2,58 \%$ \\
\hline Áreas residenciais & 2333887,927 & $25,00 \%$ \\
\hline Tecido urbano contínuo & 1000072,327 & $10,71 \%$ \\
Área residencial multi-familiar & 500962,0870 & $5,37 \%$ \\
Área residencial unifamiliar & 472348,4442 & $5,06 \%$ \\
Tecido urbano descontínuo & 360505,0692 & $3,86 \%$ \\
\hline Infra-estruturas, equipamentos e unidades comerciais & 726548,3956 & $0,78 \%$ \\
\hline Área portuária & 12051,7153 & $0,13 \%$ \\
Estrada asfaltada e terreno associado & 530660,8655 & $5,68 \%$ \\
Rodovia e terreno associado & 6937,2391 & $0,07 \%$ \\
Caminho ou estrada sem asfaltar & 136160,1703 & $1,46 \%$ \\
\hline Área urbana verde & 40738,4054 & $0,44 \%$ \\
\hline Áreas de agricultura e silvicultura & 0 & $0,00 \%$ \\
\hline Agricultura não intensiva & 0 & $0,00 \%$ \\
\hline \multicolumn{1}{|c|}{ ÁREA TOTAL } & 9335658,674 & $100,00 \%$ \\
\hline
\end{tabular}

A orla de Balneário Camboriú foi dividida em três unidades e subdividida em 18 trechos (Figura 2), adaptando a segmentação destas áreas ao Projeto Orla. Desta forma, foi possível analisar as particularidades de cada unidade para posteriormente determinar o Grau de Artificialização e comparar essa classificação com a metodologia do projeto Orla. 
CLASSES DO MUNICÍPIO DE BALNEÁRIO CAMBORIÚ

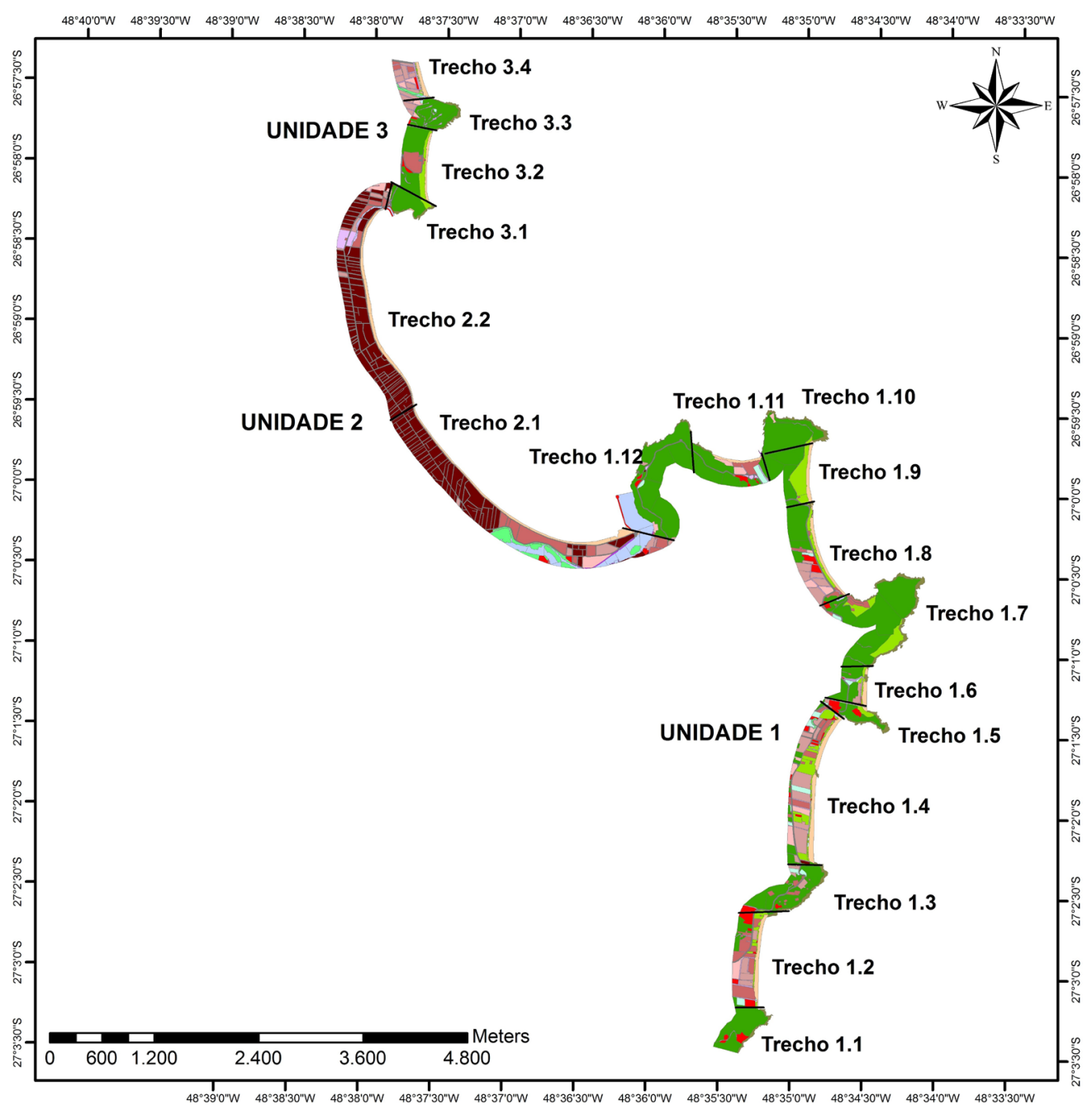

Legenda

Espaços naturais

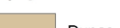

Dunas

Praia

Costão rochoso

Floresta Ombrófila Dens

Formação Pioneira com Influência Marinha

Formação Pioneira com Influência Flúvio-Marinha

$\square$ Curso d'água

Lagoa

Espaços semi-naturais

Espaço natural alterado

Espaço natural muito alterado

Áreas residenciais

Tecido urbano continuo

Área residencial multi-familiar

Área residencial unifamiliar

$\square$ Tecido urbano descontinuo

Infra-estruturas, equipamentos e

unidades comerciais

Area portuária

Estrada asfaltada e terreno associado

Rodovia e terreno associado

Caminho ou estrada sem asfaltar

Área urbana verde

\begin{tabular}{l} 
Áreas de agricultura e silvicultura \\
\hline Agricultura năo intensiva
\end{tabular}

Agricultura năo intensiva

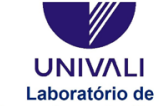

Lerenciamento Costeir

Figura 2. Classes do Município de Balneário Camboriú.

Figure 2. Classes of Balneário Camboriú City.

A Unidade 1 está localizada ao Sul do município de Balneário Camboriú e possui uma área de 1.938.550,3 $\mathrm{m}^{2}$ subdividida em 12 trechos. Nesta unidade, os Espaços Naturais cobrem $63,82 \%$ do território. Destes, $50,34 \%$ são áreas de vegetação, $5,85 \%$ são praias, $4,12 \%$ cursos d'água e $3,4 \%$ costão. Esta elevada contribuição de Espaços Naturais está relacionada à localização dos 12 trechos na regiâo da Interpraias, uma região periférica ao centro urbano, com uma porcentagem de ocupação de apenas $17 \%$ distribuídos ao longo das suas seis praias: Estaleirinho (trecho 1.2), Estaleiro (trecho 1.4), Do Pinho (trecho 1.6), Taquaras (trecho 1.8), Taquarinhas (trecho 1.9) e Laranjeiras (trecho 1.11).

No entanto, a pressão exercida pelo quase esgotamento do espaço físico na região da Praia Central está motivando lentamente a busca por essas regiōes periféricas, pois estas se encontram próximas aos grandes centros e ainda preservam sua beleza natural, sendo uma alternativa para o turismo e para a construção civil.

O trecho 1.4 apresenta a maior porcentagem de ocupaçáo por Áreas residenciais (37,33\%), seguido pelos trechos 1.2 $(31,54 \%)$ e $1.8(28,54 \%)$. Nos demais trechos a área de ocupação não chega a $10 \%$ do território.
A unidade 2 está localizada na parte central do município de Balneário Camboriú e possui uma área de 2.482.241,942 $\mathrm{m}^{2}$ subdividida em dois trechos. Esta Unidade possui a maior taxa de ocupação de todo o município com 74, 17\%. Esse valor elevado está relacionado à localização dos trechos 2.1 e 2.2 na Praia Central de Balneário Camboriú. Nessa unidade foi onde se iniciou o processo de urbanização da cidade, e onde hoje se localiza um grande centro urbano, praticamente saturado. Essa rápida aceleração do crescimento urbano nesta Unidade ocorreu como resposta ao turismo e aos empreendimentos imobiliários.

Deste modo, a categoria Áreas Residenciais é a mais representativa de toda a Unidade, com quase $59 \%$ deocupação. O Trecho 2.1 contém 47,59\% de Äreas Residenciais e o Trecho 2.2 possui $67 \%$. Dentro dessa categoria, a classe com maior valor é a de Tecido Urbano Contínuo com 47,59\% de presença em toda a Unidade. Os Espaços Naturais presentes nessa área devem-se principalmente aos Cursos d'água $(9,82 \%)$, ao qual o Rio Camboriú oferece uma enorme contribuição. As Infra-estruturas, Equipamentos e Unidades Comerciais estão presentes na maioria como Estradas Asfaltadas, associadas aos tecidos urbanos. 
A unidade 3 está localizada ao Norte do município de Balneário Camboriú e possui uma área de 1.008.286,306 $\mathrm{m}^{2}$ subdividida em 4 trechos. Sua divisão no Projeto Orla é feita em 5 trechos, porém devido a falta de informaçáo na delimitaçáo destas áreas, o presente trabalho adaptou para apenas quatro trechos, homogeneizando alguns segmentos que possuem as mesmas características (3.1, 3.2 e 3.3) e dividindo outro trecho (3.5) em dois, que ao contrário dos primeiros, apresenta diferentes características muito particulares. Por conseguinte, os trechos apresentados neste estudo são: Trecho 3.1 (3.1+3.2+3.3 do Projeto Orla), Trecho 3.2 (3.4 do Projeto Orla), Trechos 3.3 e 3.4 (3.5 do Projeto Orla).

Os Espaços Naturais predominam, com 74,29\% de cobertura de solo. A vegetação dessa unidade ocupa $64 \%$ do espaço, cobrindo os promontórios que dividem as duas praias presentes nesta unidade: do Buraco (trecho 3.2) e dos Amores (trecho 3.4). A primeira tem o acesso isolado, apenas por trilha ou por um resort. A praia dos Amores é bastante freqüentada pois pertence ao trecho com maior ocupação da Unidade 3, fazendo divisa ao Norte com o município de Itajaí.

Esta Unidade apesar de possuir um maior valor de solo não ocupado $78,57 \%$, também apresenta ocupação relativamente alta, o equivalente a $24 \%$ do seu território. Áreas Residenciais ocupam 16,75\%. O trecho 3.4 possui o maior valor em termos de Áreas Residenciais, com 52,11\%. Enquanto nos demais trechos predominam os Espaços Naturais, com valores acima de $78 \%$.

Após a classificação de ocupação do solo, foi determinado o Nível de Artificialização de cada classe (Figura 3), através do painel dos especialistas.

\section{NÍVEL DE ARTIFICIALIZAÇÃO DO MUNICÍPIO DE BALNEÁRIO CAMBORIÚ}

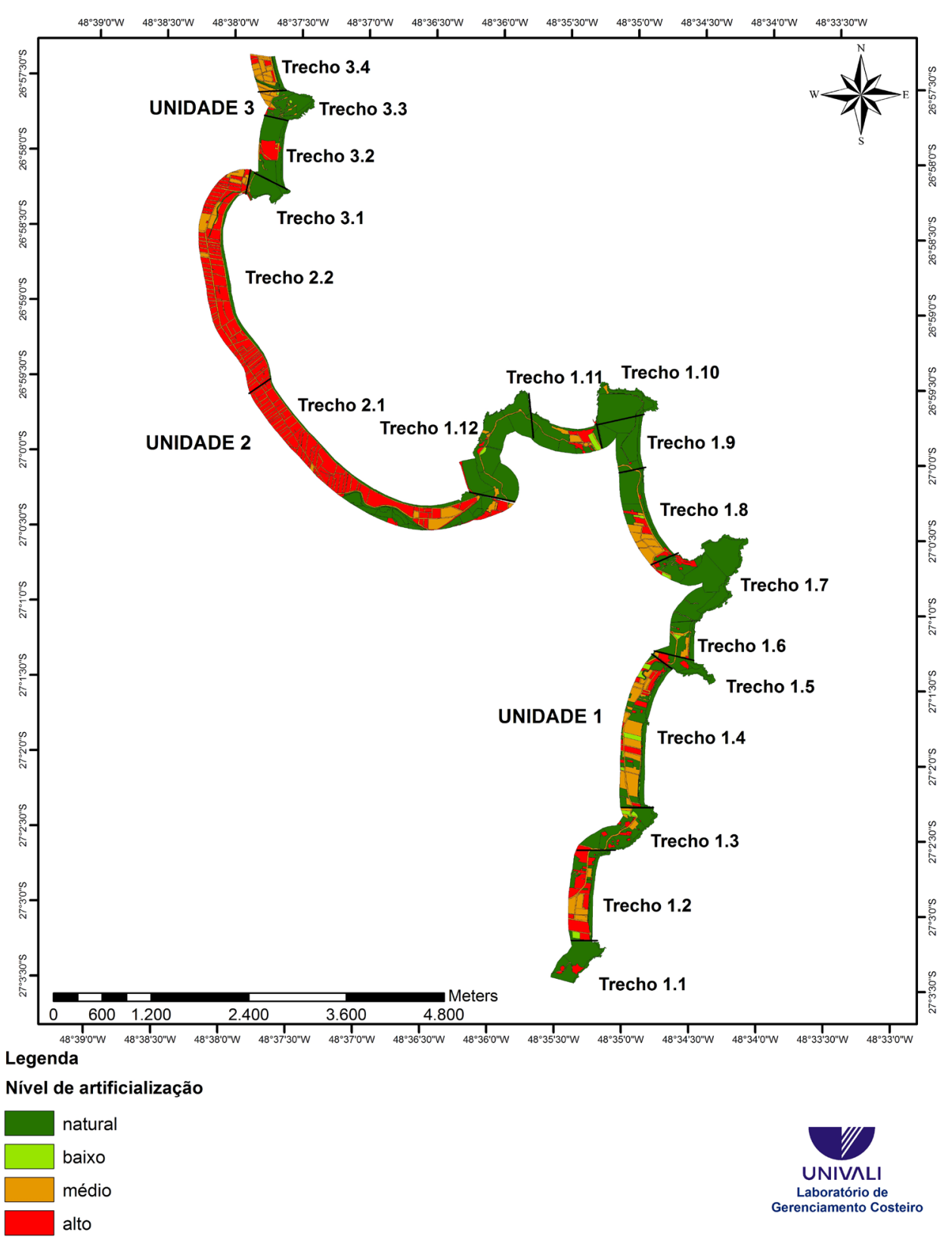

Figura 3. Nível de Artificialização do Município de Balneário Camboriú

Figure 3. Artificialization Level by class type of Balneário Camboriú City. 
A predominância do considerado Alto Nível de Artificialização ocorre nos Trechos 2.1 e 2.2, com 44\% e $63 \%$, respectivamente. O Trecho 3.4 apresenta a maior porcentagem de Médio Nível de Artificialização, com $63,22 \%$.

A partir da distribuição dos Níveis Alto, Médio, Baixo e Natural, foi possível classificar cada trecho de acordo com o Grau de Artificialização. Para isso, foi considerada a porcentagem de ocupaçáo Natural sobre a porcentagem de ocupação Artificial (soma dos Níveis Alto, Médio e Baixo) e a porcentagem do Alto Nível de Artificialização de cada trecho.

Cabe ainda colocar que o maior valor do Nível Alto de Artificialização pertence a Unidade 2, reafirmando sua posição de maior índice de ocupação em relação as demais Unidades. As Unidades 1 e 3 apresentam valores similares de Artificialização, com o Nível Natural predominando sobre os demais, seguido do Médio Nível de Artificialização e do Alto Nível de Artificialização.

Já a Figura 4 ilustra o Grau de Artificialização total dos Trechos do município de Balneário Camboriú. Através das porcentagens do Nível de Artificialização, é possível generalizar não somente o Grau de Artificialização de cada trecho, mas também das Unidades .

Desta forma, de acordo com os percentuais de ocupação Natural/Artifical e os percentuais de Alto Nível de Artificialização as Unidades 1 e 3 foram classificadas como Semi-naturais e a Unidade 2 classificada como Artificial.

GRAU DE ARTIFICIALIZAÇÃO DOS TRECHOS DO MUNICÍPIO DE BALNEÁRIO CAMBORIÚ

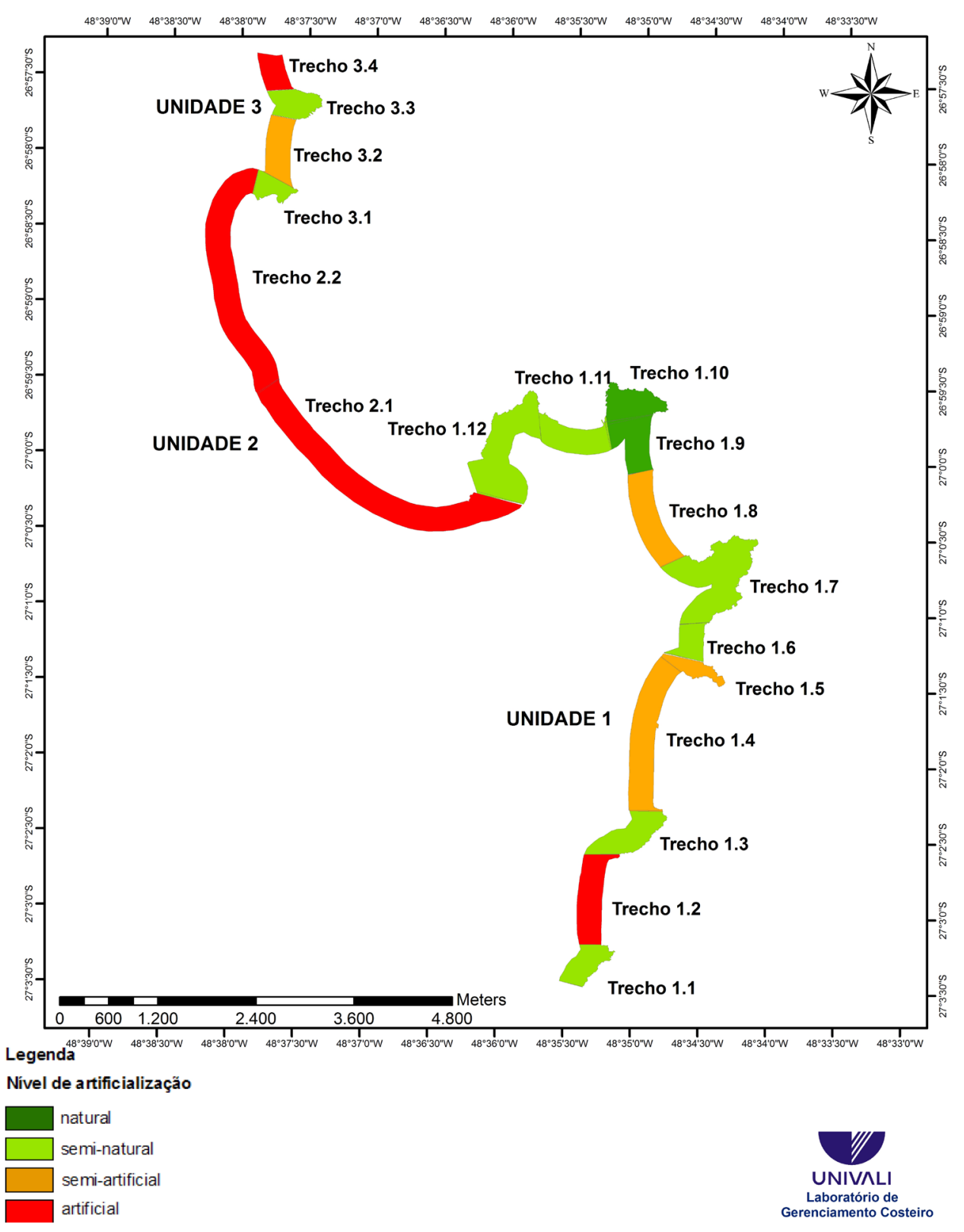

Figura 4. Grau de Artificialização dos trechos do Município de Balneário Camboriú. Figure 4. Artificialization Degree by segments of Balneário Camboriú City. 
Desta forma, de acordo com os percentuais de ocupação Natural/Artifical e os percentuais de Alto Nível de Artificialização as Unidades 1 e 3 foram classificadas como Semi-naturais e a Unidade 2 classificada como Artificial. (Figura 5).

\subsection{A artificializaçáo do Município de Balneário Camboriú}

O processo de artificialização de Balneário Camboriú está relacionado, segundo Reis (2008), com um processo que se iniciou em 1950 e se intensificou nos anos de 1970, a partir da construção da rodovia BR-101. Além da facilitação do acesso, a pavimentação da rodovia também levou a maior integração dos municípios na economia do país, sendo o ponto de partida para entendermos o processo da acentuada urbanização do município de Balneário Camboriú, influenciada pela tendência mundial de ocupaçáo massiva. (Vidal \& Ferreira, 2007).

A construçáo da rodovia acompanhando a linha da costa foi muito conveniente na valorização de terrenos na orla, incluindo as propriedades do político João Goulart, presidente do Brasil entre 1961 e 1964, o qual desde a década de 50 freqüentava o litoral da região, e possuía uma residência em Balneário Camboriú onde passava suas férias. Segundo dados do portal internet da Prefeitura Municipal de Balneário Camboriú, na época a praia chegou a ser conhecida como a "Praia Presidencial".

\section{GRAU DE ARTIFICIALIZAÇÃO DAS UNIDADES DO MUNICÍPIO DE BALNEÁRIO CAMBORIÚ}

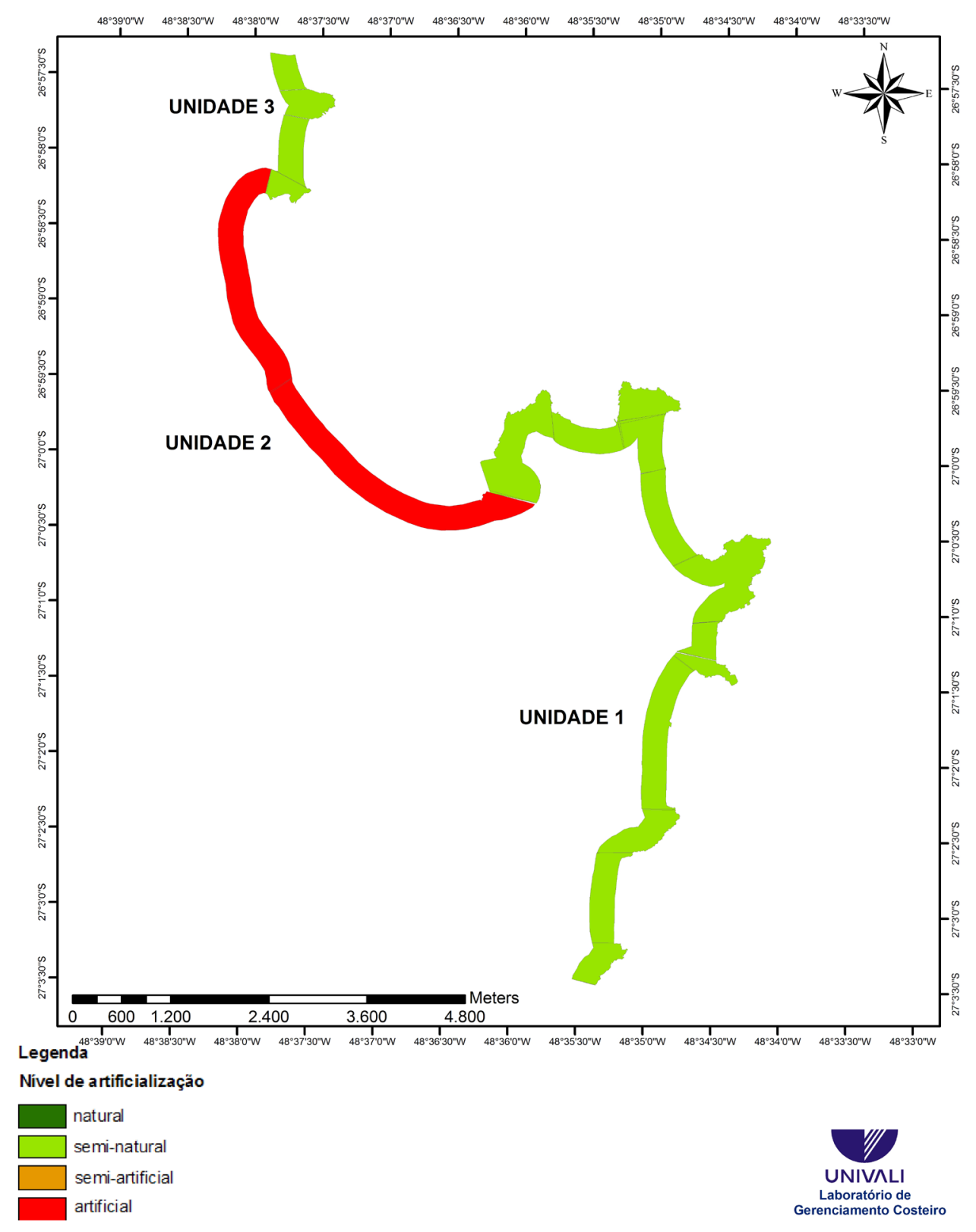

Figura 5. Grau de Artificialização das unidades do Município de Balneário Camboriú Figure 5. Artificialization Degree by Landscape Units of Balneário Camboriú City. 
Com a concretização do Plano Rodoviário Nacional e a construção da rodovia paralela à linha da costa, ocorreu a acelerada proliferaçáo de empreendimentos imobiliários e lotes urbanos nas terras litorâneas. Mas a verdadeira explosão das taxas de urbanização, de acordo com Vidal \& Ferreira (2007), ocorreu na década de $80 \mathrm{em}$ diante, quando a crise de investimentos industriais tornou a compra de terras e imóveis nessa região um investimento seguro, "drenando para a especulação imobiliária significativa parcela do capital acumulado nos anos do surto desenvolvimentista dos anos 60/70". Isso ocorreu devido a investimentos de capitalistas de origem germânica na área industrial em imóveis na região centro-norte do estado catarinense, a qual apresentava ofertas de terras abundantes e de baixo custo.

$\mathrm{O}$ investimento na construção civil também teve como conseqüência o aumento das segundas residências, como alternativa de lazer para os que habitavam áreas industriais, como Blumenau e Joinville, próximas do litoral e, mais tarde, como investimento de giro de capital, já que em muitas áreas a valorização anual chega a $40 \%$.

A expansão das atividades turísticas, através de investimentos públicos e privados cada vez maiores e a atração da mão-de-obra que migra de várias regióes do Brasil para dar suporte à construção civil, complementam os fatores que levam o município de Balneário Camboriú ao rápido crescimento urbano e à artificialização da paisagem natural num curto espaço de tempo. Tal crescimento gerou problemas de infra-estrutura e planejamento, além de um processo acelerado de verticalização.

Assim, a princípio o crescimento ocorreu principalmente na planície costeira, e em uma praia de natureza dissipativa de longa extensão (Trechos 1.2, 2.1 e 2.2). Entretanto, o aumento acelerado da população esgotou a capacidade de suporte da orla marítima, saturando o centro urbano em inúmeros aspectos (trânsito, disponibilidade de água, etc), fadando assim as regiōes periféricas ao mesmo intenso processo de artificialização, como é o caso do município de Camboriú.

\subsection{Comparaçáo da Classificaçáo com o Projeto Orla}

As análises do Projeto Orla quanto ao tipo de classificação da orla ocorrem de maneira qualitativa de acordo com os atributos naturais e as tendências de ocupação observadas em campo. Neste sentido, o Projeto Orla desenvolveu três classes genéricas de uso e ocupação, considerando níveis de preservação dos ambientes naturais da orla: $\mathrm{A}, \mathrm{B}$ e C

Em contrapartida, a metodologia para classificação da orla neste trabalho foi efetuada de maneira quantitativa, através da análise de ocupação do solo por vetorizaçáo utilizando imagens de satélite, o que proporciona um maior detalhamento e definição dos diversos níveis de artificialização. Desta forma, foram criadas quatro classes para determinação do nível de artificialização: Natural, Semi-natural, Semiartificial e Artificial.

A diferenciação quanto ao número de classes nas duas metodologias, sendo 3 classes no Projeto Orla e 4 classes na metodologia de Análise de Artificialização, dificulta a comparação dos resultados e questiona a generalização pouco abrangente do Projeto Orla. Na Tabela 4 estão expostas as equivalências entre ambas as metodologias:

Considerando as equivalências propostas, foram feitas comparações destacadas na tabela 5.

De acordo com a metodologia de Artificialização, existem dois trechos classificados como Naturais. Os mesmos espaços receberam a classificação A do Projeto Orla. Este, ainda classifica mais sete trechos com a letra $\mathrm{A}$, onde seis enquadram-se como Semi-naturais e um como Semi-artificial. Em relação à classe $\mathrm{B}$ existem sete trechos selecionados, os quais na classificação quanto a artificialização dois são Seminaturais, três são Semi-artificiais e dois são Artificiais. Por

Tabela 4. Equivalências entre as classes propostas pelo Projeto Orla e pelo trabalho presente.

Table 4. Equivalences between the classes proposed by the Project Orla and this work.

\begin{tabular}{|c|c|c|c|}
\hline & TRECHOS & CLASSES PROJETO ORLA & CLASSIF GRAU ARTIF \\
\hline \multirow{12}{*}{$\begin{array}{c}\text { UNIDADE } 1 \\
\text { BC }\end{array}$} & 1.1 & $\mathrm{~A}$ & Semi-natural \\
\hline & 1.2 & B & Artificial \\
\hline & 1.3 & A & Semi-natural \\
\hline & 1.4 & $\mathrm{~B}$ & Semi-artifical \\
\hline & 1.5 & A & Semi-artifical \\
\hline & 1.6 & $\mathrm{~A}$ & Semi-natural \\
\hline & 1.7 & $\mathrm{~A}$ & Semi-natural \\
\hline & 1.8 & B & Semi-artifical \\
\hline & 1.9 & $\mathrm{~A}$ & Natural \\
\hline & 1.10 & $\mathrm{~A}$ & Natural \\
\hline & 1.11 & $\mathrm{~B}$ & Semi-natural \\
\hline & 1.12 & $\mathrm{~A}$ & Semi-natural \\
\hline \multirow{2}{*}{$\begin{array}{c}\text { UNIDADE } 2 \\
\text { BC }\end{array}$} & 2.1 & $\mathrm{C}$ & Artificial \\
\hline & 2.2 & $\mathrm{C}$ & Artificial \\
\hline \multirow{4}{*}{$\begin{array}{c}\text { UNIDADE } 3 \\
\text { BC }\end{array}$} & 3.1 & $\mathrm{~A}$ & Semi-natural \\
\hline & 3.2 & $\mathrm{~B}$ & Semi-artifical \\
\hline & 3.3 & $\mathrm{~B}$ & Semi-natural \\
\hline & 3.4 & B & Artificial \\
\hline
\end{tabular}


último, a classe $\mathrm{C}$ possui todas as áreas classificadas como Artificiais.

Dentro destas classes, alguns resultados do Projeto Orla são contraditórios. Por exemplo, os trechos 1.3, 1.5 e 1.6 apresentam mais de $20 \%$ de alteração antrópica e pertencem à classe $\mathrm{A}$ enquanto o trecho 1.11 , com $14 \%$ de alteração, pertence à classe $\mathrm{B}$. Outros trechos classificados como Artificiais, com mais de $43 \%$ de alteração na ocupação do solo estão classificados como B.

As contradiçõos existentes em relação ao enquadramento de trechos semelhantes em diferentes classes do Projeto Orla indicam a necessidade de se obterem níveis intermediários de classificação, onde seja possível qualificar áreas com baixo e médio Grau de Artificialização, porém com impactos significantes.

O Projeto Orla possui várias etapas de construção para a aplicaçáo de diretrizes gerais de disciplinamento de uso e ocupação do espaço. Para isso, fornece documentos que apresentam desde a base política-institucional, análises comparativas acerca das experiências internacionais sobre a matéria com valor técnico/acadêmico e um manual de gestão que, por meio de uma linguagem técnica simplificada, orienta a classificação e a caracterização da situação atual, a fim de diagnosticar a situação atual e compor cenários desejados e respectivas açôes de intervenção para alcançá-los.

Portanto, o presente estudo analisa apenas a eficácia da classificaçáo do Projeto Orla e não questiona seus demais processos de articulação para a gestáo integrada da orla marítima, já que este se apresenta de forma didática e devidamente ilustrada, possibilitando a participação dos diversos atores sociais no processo de gestão participativa. Desta forma, a metodologia aqui desenvolvida visa complementar as análises do Projeto Orla, validando sua classificação qualitativa com valores concretos de percentual de ocupação.

Tabela 5. Comparação das classes do Projeto Orla com o as classes de Artificialização.

Table 5. Comparison of classes proposed by the Project Orla with classes of Artificialization Degree.

\begin{tabular}{|c|c|}
\hline CLASSES PROJETO ORLA & $\begin{array}{c}\text { CLASSES NÍVEL } \\
\text { ARTIFICIALIZAÇÃO }\end{array}$ \\
\hline $\begin{array}{c}\text { Classe A: baixíssima ocupação, } \\
\text { com paisagens com alto grau de } \\
\text { originalidade e baixo potencial de } \\
\text { poluição. }\end{array}$ & NATURAL \\
\hline $\begin{array}{c}\text { Classe B: tipos que apresentam } \\
\text { de baixo a médio adensamento } \\
\text { de construções e população } \\
\text { residente, com indícios de } \\
\text { ocupação recente, paisagem } \\
\text { parcialmente antropizadas e } \\
\text { médio potencial de poluição. }\end{array}$ & SEMI-NATURAL / SEMI- \\
\hline $\begin{array}{c}\text { Classe C: médio a alto } \\
\text { adensamento de construções } \\
\text { e populaçóes residentes, } \\
\text { com paisagens antropizadas, } \\
\text { multiplicidade de usos e alto } \\
\text { potencial de poluição. }\end{array}$ & ARTIFIAL \\
\hline
\end{tabular}

\section{CONCLUSÁO}

A metodologia aqui apresentada possibilitou gerar um banco de dados do município de Balneário Camboriú com a quantificação das distintas categorias de ocupação e a distribuição espacial dos diferentes Graus de Artificialização em cada área.

Os mapas gerados permitiram a visualização dessas diferentes etapas do projeto, ilustrando as classes de ocupação, os níveis de atificialização destas classes e o grau de artificialização total, o qual generalizou os níveis de artificialização de cada trecho e de cada unidade.

Pode-se observar nos mapas, que o grau de artificialização total dos trechos permite uma análise profunda e específica, o que facilita a aplicação de um diagnóstico mais fiel à realidade de cada trecho.

Balneário Camboriú apresentou uma unidade Artificial e duas unidades Semi-naturais. A área Artificial está no limite da sua máxima ocupação, comprometendo o futuro das áreas Semi-naturais, as quais serão os posteriores alvos do setor imobiliário e da construção civil.

A partir da quantificação do Grau de Artificialização, também foi possível comparar o modelo proposto com o Projeto Orla, afim de auxiliar no processo de tomada de decisão.

A metodologia aqui desenvolvida visou complementar as análises do Projeto Orla, validando sua classificação qualitativa com valores concretos de percentual de ocupação, possibilitando uma melhor identificação do problema e, conseqüentemente, um diagnóstico coerente com a realidade dos municípios.

O método de análise visual em imagens de alta resolução demonstrou ser uma ótima ferramenta de classificação de ocupação do solo. Desta forma, foi possível desenvolver uma metodologia barata, a qual pode ser utilizada tanto em projetos litorâneos, como o Projeto Orla, por exemplo, como em outros projetos de planejamento urbano de qualquer prefeitura municipal.

É ainda oportuno neste trabalho sugerir futuros monitoramentos das áreas usando a mesma metodologia de forma a acompanhar a evolução dos cenários encontrado nessa pesquisa. Cabe destacar que o mesmo método já está sendo utilizado em mais quatro municípios do litoral de Santa Catarina e cujos resultados agora evoluíram para a análise do processo de artificialização também da área marinha.

\section{BIBLIOGAFIA}

Alves, F.L.; Silva, C.P.; Pinto, P. (2007) - The assessment of the coastal zone development at a regional level: the case study of Portugal central area. Journal of Coastal Research (ISSN: 0749-0208), SI 50 (ICS2007 Proceedings): 72-76. Disponível em http://www.griffith.edu.au/conference/ ics2007/pdf/ICS015.pdf.

Bossard, M.; Feranec, J.; Otahel, J. (2000) - CORINE land cover technical guide - Addendum 2000. European Environment Agency, Technical report No 40, 105p., Copenhagen, Dinamarca. Disponível em http:/www. $\mathrm{dmu} . \mathrm{dk} /$ fileadmin/Resources/DMU/Udgivelser/ CLC2000/technical_guide_addenum.pdf 
EEA (2006) - The changing faces of Europe's coastal areas. 107p., European Environment Agency (EEA), Office for Official Publications of the European Communities, Luxembourg. ISBN: 9291678422. Disponível em http://www.eea.europa.eu/publications/eea_report_2006_6

Herrero, L.M.J. (2008) - Ocupación del suelo en España y cambio global: artificialización, urbanización y litoralización. In: Cambio Global Espanã 2020's: El reto es actuar, pp.94-99, Fundación CONAMA, Madrid, Espanha. ISBN: 9788461278282. Disponível em: http://www.conama9.org/bo/bancorecursos/banco_ imagenes/conama9/Informe $\% 202020 /$ ocupacion $\% 20$ del $\% 20$ suelo\%20en $\% 20$ Espana $\% 20 y \% 20$ cambio $\% 20$ global.\%20Artificializacion, $\% 20$ urbanizacion $\% 20 y \% 20$ litorizacion.pdf

Lacasa, R.M. (2009) - Methodological approach to assessing and classifying artificialization process in the seashore areas: a case study on the Porto Belo Peninsula, Southern Brazil. Dissertação de Mestrado, 115p., Faculdade de Ciências e Tecnologia, Universidade do Algarve, Faro, Portugual. (Não Publicado)

Marrubio, P.M. (2004) - La percepción remota y La tecnologia SIG: uma aplicación em ecologia de paisaje. Revista Internacional de Ciencia y Tecnologia de La Información Geográfica (ISSN: 1578-5157), 4:1-24. Disponível em http://geofocus.rediris.es/docPDF/Articulo1_2004.pdf

MEA (2005) - Ecosystems and Human Well-being: Wetlands and Water - Synthesis. Millennium Ecosystem Assessment (MEA), 68p., World Resources Institute, Washington, DC. U.S.A. ISBN: 1569735972. Disponível em http://www. maweb.org/documents/document.358.aspx.pdf

POLETTE, Marcus (2004) - Aplicação do Modelo de Desenvolvimento de Balneários - MDB para fins de Gerenciamento Costeiro Integrado. Universidade do Vale do Itajaí, Itajaí, SC, Brasil. (Não Publicado).

Prefeitura Municipal de Balneário Camboriú (2003) Plano de Intervenção na Orla Marítima do Município de Balneário Camboriú. 86p., Balneário Camboriú, SC, Brasil. Disponível em www.sds.sc.gov.br/index. php?option=com_docman

Reis, Almir F. (2008) - Forma Urbana, Paisagem e Meio Ambiente. Estudo dos Processos de Crescimento UrbanoTurístico no Litoral Catarinense. X Colóquio Internacional de Geocrítica. Barcelona, Espanha. Disponível em http://www.ub.edu/geocrit/-xcol/194.htm
Sanjaume, E.; Pascual, J.E.P. (2008) - Cambios de tendências recientes en la evolución costera del golfo de Valencia: análisis espacialis y sedimentológicos. Actas de las Jornadas Técnicas "Las nuevas técnicas de información geográfica al servicio de la gestión de zonas costeras: Análisis de la evolución de playas y dunas", Universidad Politécnica de Valencia, Espanha. ISBN: 9788483633366. Disponível emhttp://cgat.webs.upv.es/bigfiles/costas/Ponencias_ actas/01.E.Sanjaume,J.E.Pardo.pdf

Silva,L.H.M.M.(2007)-Modelo de análisepara oentendimento do processo de artificializaçấo do litoral. Estudo de caso da praia de Jurerê Internacional - Florianópolis (SC) e a Praia Central de Balneário Camboriú (SC). Trabalho de conclusão de curso, 186p., Faculdade de Oceanografia, Universidade do Vale do Itajaí, Itajaí, SC, Brasil.

Uda, T.; Hoshigami, Y.; Seino, S.; Ozawa, H. (2007) Increase in disaster potential caudes by excess use of land in coastal zone. Journal of Coastal Research (ISSN: 0749-0208), SI 50 (ICS2007 Proceedings): 140-146. Disponível em http://www.griffith.edu.au/conference/ ics2007/pdf/ICS028.pdf.

UN-HABITAT (2008) - State of the world's cities 2008/2009: Harmonious Cities. 259p., United Nations Human Settlements Programme (UN-HABITAT), Earthscan Publ., London, U.K. / Sterling, VA, U.S.A. ISBN: 9789211320107. Disponível em http://www.unhabitat.org/ pmss/listItemDetails.aspx?publicationID $=2562$.

Vidal, L.M.; Ferreira, L.S. (2007) - A infra-estrutura portuária catarinense no século $\mathrm{XX} .12^{\circ}$ Encuentro de Geógrafos de América Latina, Montevideo, Uruguay. ISBN: 9789974819405. Disponível em http://egal2009. easyplanners.info/area01/1163_Vidal_Leandro_Moraes.pdf.

Zamboni, A.; Vilanova, R.R. (coord.) (2006) - Projeto Orla. Manual de Gestão. 88p., Ministério do Meio Ambiente, Secretaria de Qualidade Ambiental e Ministério do Planejamento, Orçamento e Gestão , Secretaria do Patrimônio da União, Brasília, DF, Brasil. ISBN: 8577380505. Disponível em http://www. planejamento.gov.br/secretarias/upload/Arquivos/spu/ publicacao/081021_PUB_ProjOrla_manGestao.pdf

Zújar, J. O.; Lama, A. V. (2006) - Evolución del suelo urbano/alterado em el litoral de Andalucia. Geofocus: Revista Internacional de Ciência y Tecnologia de La Información Geográfica (ISSN: 1578-5157). Espanha, 7:7399. http://geofocus.rediris.es/2007/Articulo5_2007.pdf 